\title{
Quality of Life in Children with Obsessive-Compulsive Disorder
}

\section{Qualidade de Vida em Crianças com Perturbação Obsessiva-Compulsiva}

\author{
Joana VIEIRA* $\rrbracket^{1}$, Filipa RAMALHO E SILVA*2 \\ Acta Med Port 2016 Sep;29(9):549-555 - http://dx.doi.org/10.20344/amp.7726
}

\section{ABSTRACT}

Introduction: Obsessive-compulsive disorder is a psychiatric disorder stated as one of the most debilitating diseases in the developed world. However, not much is known about how this disease impairs patients' quality of life in children.

Material and Methods: We conducted a research in PubMed and Thomson Reuters Web Of Science using the following terms: 'Quality of life', 'Obsessive-compulsive disorder', 'Child', 'Pediatrics' and 'Adolescent'. Of the 138 papers retrieved with this search, five articles corresponded to the aim of this review. We analyzed quality of life in children with obsessive-compulsive disorder comparing with general population and searching the relation with other clinical variables such as sex, age, comorbidities, symptoms dimension, symptoms severity, family accommodation and quality of life.

Results: Albeit studies results not being concordant regarding the different dimensions analyzed, our findings pointed to an overall decrease of quality of life in children with obsessive-compulsive disorder. The presence of co-morbidities, symptoms severity and obsessions with harm/aggression content are the variables that have a higher influence in quality of life levels.

Discussion: The small number of articles found and the fact that their methodology was extremely heterogeneous made it difficult to state robust conclusions. Despite that, our findings agree with other studies in adults.

Conclusion: Quality of life in children and adolescents with obsessive-compulsive disorder must be better explored in future researches. We suggest the introduction of quality of life as a routinely used instrument in patient's assessment and in treatment response evaluation.

Keywords: Adolescent; Child; Obsessive-Compulsive Disorder; Quality of Life.

\section{RESUMO}

Introdução: A perturbação obsessiva-compulsiva foi apontada como uma das doenças mais debilitantes do mundo desenvolvido. Contudo, muito pouco é conhecido sobre esta doença relativamente ao modo como ela afeta a qualidade de vida das crianças.

Material e Métodos: Conduzimos uma pesquisa na PubMed e Thomson Reuters Web Of Science usando os seguintes termos de pesquisa: 'Quality of life', 'Obsessive-compulsive disorder', 'Child', 'Pediatrics' e 'Adolescent'. Dos 138 artigos obtidos, cinco correspondiam aos objetivos desta revisão. Analisámos a qualidade de vida de crianças com perturbação obsessiva-compulsiva comparando com a população geral e procurando a relação com outras variáveis clinicas como o sexo, idade, comorbilidades, categoria de sintomas, severidade dos sintomas e acomodação familiar.

Resultados: Apesar dos estudos não serem concordantes relativamente às diferentes dimensões analisadas, os nossos resultados apontam para um decréscimo global da qualidade de vida em crianças com perturbação obsessiva-compulsiva. A presença de comorbilidades, a severidade dos sintomas e as obsessões de agressão/dano são as variáveis que têm maior influência na qualidade de vida dos pacientes.

Discussão: O reduzido número de artigos encontrados e o facto de estes apresentarem uma metodologia extremamente heterogénea torna difícil alcançar conclusões robustas. Apesar disto, os nossos resultados são concordantes com estudos realizados em adultos. Conclusão: A qualidade de vida em crianças e adolescentes deve ser melhor explorada em futuros estudos. Sugerimos a introdução da qualidade de vida como instrumento usado rotineiramente para avaliar a resposta ao tratamento e evolução do paciente.

Palavras-chave: Adolescente; Criança; Qualidade de Vida; Perturbação Obsessiva-Compulsiva.

\section{INTRODUCTION}

Obsessive-compulsive disorder (OCD) in children and adolescents (pediatric OCD) is a psychiatric entity that includes a wide range of symptoms dimensions. This condition is characterized by repetitive unwanted thoughts or images that are involuntary, distressing, unpleasant and impossible to control (obsessions)..$^{1}$ Obsessions cause the development of repetitive behaviors or mental acts that are time-consuming and driven by restrict rules (compulsions). Compulsions usually surge as an attempt to reduce anxiety caused by obsessions. ${ }^{2}$ Common obsessions include contamination, aggressive, sexual, and religious obsessions, as well as preoccupation about making things 'just right'. On the other side, we have washing and cleaning, checking, repeating and ordering as common compulsions. ${ }^{1}$

In this paper we don't aim to differentiate younger children from adolescents. Hence, we will nominate as 'children' or 'pediatric' everything related with individuals under 18 years-old, unless the studies we are quoting make any kind of differentiation we find relevant to expose.

It is common for children to present more than one obsession and/or compulsion at the same time. ${ }^{2}$ The features that have to do with cleaning are the most common

\footnotetext{
${ }^{*}$ Co-primeiro autor.

1. Faculdade de Medicina. Universidade do Porto. Porto. Portugal.

2. Departamento de Neurociências Clínicas e Saúde Mental. Faculdade de Medicina. Universidade do Porto. Porto. Portugal.

$\triangle$ Autor correspondente: Joana Vieira. joanaidsvieira@gmail.com

Recebido: 10 de abril de 2016 - Aceite: 22 de agosto de 2016 | Copyright @ Ordem dos Médicos 2016
} 
in affected children, being followed by repetition, checking and aggressive thoughts. ${ }^{3}$

Many studies have been developed in order to understand OCD etiology but it is still not very clear. OCD is known to be a multifactorial disease with a strong genetic component but also environmental involvement. In the past 10 - 15 years, some evidences of streptococcus infection causality have also been shown. Furthermore, it is clear the importance of serotoninergic, dopaminergic and glutamatergic systems as well as orbitofrontal cortex functionality in OCD development. ${ }^{1}$ Some recent investigations also found an abnormal stress response, measured by higher levels of perceived stress and cortisol levels, in patients with OCD, with a more positive correlation with obsession symptoms. This dysfunction may also be an explanation for OCD etiology. ${ }^{4}$

OCD diagnostic criteria include the presence of obsessions or compulsions present for long periods of time that must be a source of distress and that significantly interfere with occupational, social or other important areas of functioning. The actions must not be pleasurable for the patient and thoughts must surge repetitively even if the patient tries to resist them. Besides that, these symptoms can't be attributed to any substance intake or other medical condition. The ICD-10 and DSM-V diagnostic criteria include the conditions described below and are commonly used to establish OCD diagnosis. ${ }^{5,6}$

There is no specific pediatric instrument different from the ones used in adults. Regardless of the method, it is always necessary in children to differentiate obsessions or compulsions from normal developmental ritualized actions with parents or their toys, for example. ${ }^{3}$ Typically OCD remains undetected for some years after the disease onset, which may boost the chronic course that this disorder usually takes. ${ }^{1,3}$

An epidemiological study published in 1988 established an estimated prevalence of $3 \%$ of OCD in pediatric age ${ }^{7}$ and some other studies demonstrated that in younger children this disease is lightly more prevalent in boys than girls, in a ratio of about 3:2. Despite that, in adolescents there is not a significant difference. ${ }^{3}$ Age of onset is mostly between 7.5 and 12.5 years. $^{2}$

Although we may find OCD in children in its 'pure' form, the existence of a co-morbid illness is very frequent. ${ }^{2}$ The most common co morbidities are anxiety disorders, depression, attention deficit-hyperactivity disorder (ADHD) and Tic disorders (as Tourette's syndrome). ${ }^{2,3}$ In fact, 39\% of children and $62 \%$ of adolescents with OCD have major depressive symptoms, and Tourette's syndrome is present in $25 \%$ of children and $9 \%$ of adolescents. ${ }^{8}$

Treatment for pediatric OCD consist mainly in cognitive behavioral therapy (CBT) and pharmacological therapy with selective serotonin reuptake inhibitors (SSRI's) as first choice drugs ${ }^{1,2}$.

It must be noted that the World Health Organization (WHO) ranked OCD as one of the most impairing disease in the developed world. ${ }^{9}$ Health-related quality of life (HRQoL) is a very wide concept that may have some peculiarities when being assessed in children. Only a generic instrument allows a comparison between different disorders and healthy children and adolescents. This measurement instrument must also be age-appropriate in order to take in consideration the subject's cognitive development. HRQoL can be evaluated using profile and index measures. Index measures collect individual ratings to reach a global score. Therefore they are mostly used in epidemiological studies. On the other hand, profile measures are more suitable for clinical research since they make an overview on individual dimensions of quality of life (physical and emotional wellbeing, social support, relationship with friends and parents, school environment, etc.). ${ }^{10}$ The instruments presented in Table 1 complete all this criteria and may be used to evaluate $\mathrm{QoL}$ in pediatric age. ${ }^{10,11}$

Health related quality of life is an important focus in pediatric OCD since this condition very often takes a chronic course and it is well-documented in adults the effect of the disease in their quality of life and functional impairment. In spite of being an empirical knowledge that young people with OCD also experience difficulties at school, problematic peer relations and try to avoid recreational group activities,

Table 1 - Some quality of life instruments

\begin{tabular}{|c|c|c|c|c|}
\hline Name & Evaluated dimensions & Scores & Target population & Observations \\
\hline $\begin{array}{l}\text { Revised Children's } \\
\text { Quality of Life } \\
\text { Questionnaire (KINDL-R) }\end{array}$ & $\begin{array}{l}\text { Physical, emotional, family, } \\
\text { social and school-related } \\
\text { well-being; } \\
\text { self-esteem. }\end{array}$ & $\begin{array}{l}\text { One score for each } \\
\text { dimension. } \\
\text { Total score. }\end{array}$ & $\begin{array}{l}\text { Healthy and ill } \\
\text { pediatric population }\end{array}$ & $\begin{array}{l}12 \text { or } 24 \text { items (depends } \\
\text { on age) } \\
\text { Self-report and proxy- } \\
\text { report versions }\end{array}$ \\
\hline $\begin{array}{l}\text { Pediatric Quality of Life } \\
\text { Inventory (PedsQoL) }\end{array}$ & $\begin{array}{l}\text { Physical, emotional, } \\
\text { social and school-related } \\
\text { functioning }\end{array}$ & $\begin{array}{l}\text { Psychosocial } \\
\text { score. } \\
\text { Total score }\end{array}$ & $\begin{array}{l}\text { Healthy and ill } \\
\text { pediatric population }\end{array}$ & $\begin{array}{l}23 \text { items } \\
\text { Self-report and proxy- } \\
\text { report versions }\end{array}$ \\
\hline $\begin{array}{l}\text { World Health } \\
\text { Organization Quality } \\
\text { of Life Assessment } \\
\text { Abbreviated Version } \\
\text { (WHOQoL-BREF) }\end{array}$ & $\begin{array}{l}\text { Physical and psychological } \\
\text { health; } \\
\text { social relations; } \\
\text { environment (eg. } \\
\text { economical resources, } \\
\text { leisure activities) }\end{array}$ & $\begin{array}{l}\text { One score for each } \\
\text { domain }\end{array}$ & $\begin{array}{l}\text { Healthy and ill } \\
\text { population }\end{array}$ & $\begin{array}{l}24 \text { items } \\
\text { Self-report and proxy- } \\
\text { report versions }\end{array}$ \\
\hline
\end{tabular}


there are not many studies proving and exploring it.

Parents are often very concerned about the impact of the disease in their children's daily activities and general well-being. Quality of life is also a very important outcome to assess treatment effectiveness but rarely taken into account. Therefore, it is important to explore the children's quality of life to make a complete assessment of our patients' condition and understand in which domains of their routine is the disease most affecting them.

This review aims to analyze what is studied about QoL in children with OCD and understand if it happens to be impaired comparing with healthy children. Secondly we also aim to explore data available about other clinical variables that may be related with this QoL variance.

\section{METHODS}

We conducted a research in PubMed and Thomson Reuters Web Of Science with the query '(Obsessivecompulsive disorder) AND (Child OR Adolescents OR Pediatrics) AND (Quality of life)'. They all are MeSH terms. We did not apply any restriction in terms of year. Only English studies were included. We excluded trials involving population over 18 years-old. All the articles which content did not meet the aims of this study were excluded.

\section{RESULTS}

From the 138 papers obtained, we used five articles to construct this review.

All the studies analyzed the relation between QoL and other clinical variables. Some characteristics of the studies included in this review are described in Table 2.

\section{Comparing with general population}

Three of the included papers indicate that QoL in children with OCD is lower comparing with general population. ${ }^{12-14}$ Vivian found this significant correlation not only for total score but also for all the subscales (physical health, psychological health, social relationship and environment). ${ }^{12}$ On the other hand, one trial developed by Weidle found that children with OCD reported QoL impairment except in the subdomains of self-esteem and school. ${ }^{14}$

One trial compared QoL in children before and after treatment for OCD and the results demonstrated that QoL in children with OCD after treatment was not significantly different from the levels of general population. ${ }^{13}$

Two authors - while evaluating their population's QoL - analyzed children's impairment in their daily routines caused by the disease. Functional impairment is a concept very close to QoL that may help us predict QoL. Impairment scores in children with OCD were much higher when compared to that of the general population. Besides that, they were proved to have a strong negative relationship with emotional and social QoL. ${ }^{14,15}$

\section{Gender, age and quality of life}

This topic revealed some controversial results. While some authors found that there is no relationship between actual age, age of onset or sex and QoL in pediatric OCD patients, ${ }^{12,14}$ in Lack's study there was evidence that female patients have poorer QoL than male. ${ }^{16}$

\section{Comorbidities and quality of life}

To access the presence and severity of symptoms of other psychiatric disorders that might be present concomitantly with OCD, some authors used the Schedule for Tourette and Other Behavioral Syndromes and Clinical Diagnoses, the Yale Global Tic Severity Scale (YGTSS) and the Children's Depression Rating Scale (CDRS). Lack also aimed at clarifying the presence of internalizing and externalizing comorbid symptoms. Therefore, participants filled the Child Behavior Checklist (CBCL) corresponding to the Internalizing and Externalizing Symptom Scales.

De Caluwé and De Clerq concluded that only $8 \%$ of the variance in QoL was explained by OCD pathology. ${ }^{15}$ So the rest must be due to associated problems. Indeed, almost every studies showed the negative influence of comorbidities in QoL in patients with OCD diagnosis. ${ }^{12,14,16}$

Vivian found a strong association between depressive symptoms and QoL in their patients. Relation with anxiety symptoms was also present but with no significance. ${ }^{12}$

Weidle had results indicating that the presence of co morbidities did not influence QoL change after treatment. ${ }^{13}$ In another study made by the same author to assess quality of life in OCD children with and without comorbidity, they initially saw that only $52.3 \%$ of them did not have any co morbidity. Then they analyzed the groups with attention deficit hyperactivity disorder (ADHD), tic disorder or both, and anxiety disorder, depression or both, and their results pointed towards a tendency for lower QoL on this individuals following children's report. However, parents reported a much lower QoL with significance in all the comorbid groups, exception made for anxiety group. This decrease in QoL was observed in total score and in the subscales physical wellbeing, emotional well-being, friends and school. Still in the same study, Weidle analyzed the influence of internalizing and externalizing behavior problems in predicting QoL and concluded that all QoL subdomains were inversely related with $\mathrm{CBCL}$ scores. ${ }^{14}$ In another trial, Lack found a negative correlation between internalizing behavior symptoms and QoL in all subdomains. On the other hand, externalizing symptoms also showed to determine QoL but with no statistical significance in physical health and social functioning subscales. ${ }^{16}$

\section{Symptom dimensions and quality of life}

De Caluwé and De Clerq tried to analyze if QoL in children with OCD was influenced by the symptom domain they presented (obsessive, compulsive or order/clean/ perfect symptom domains). They concluded that obsessive symptom domain (that included aggression, guilt, sensitivity to physical appearance and somatization) was the only significantly negatively associated with father-rated QoL but only for the social, emotional and total scores. Looking more in detail, aggression was the strongest negatively related 
旁

\%

옷요

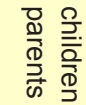

蛋

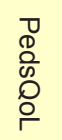

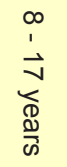

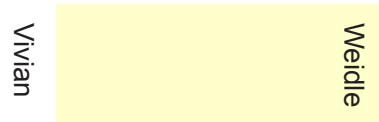

$\stackrel{\text { N }}{\mathrm{N}}$

$\vec{\omega} \vec{\omega} \underset{\omega}{\omega}$

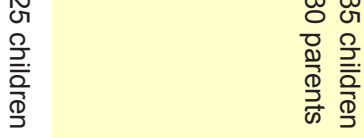

जे

$\overrightarrow{+}$
$\vec{\infty}$
$\stackrel{\vec{D}}{\infty}$
$\frac{\infty}{\omega}$

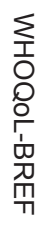

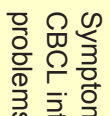

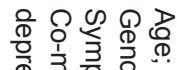

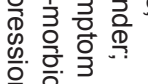

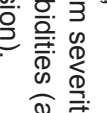

零.

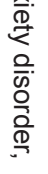
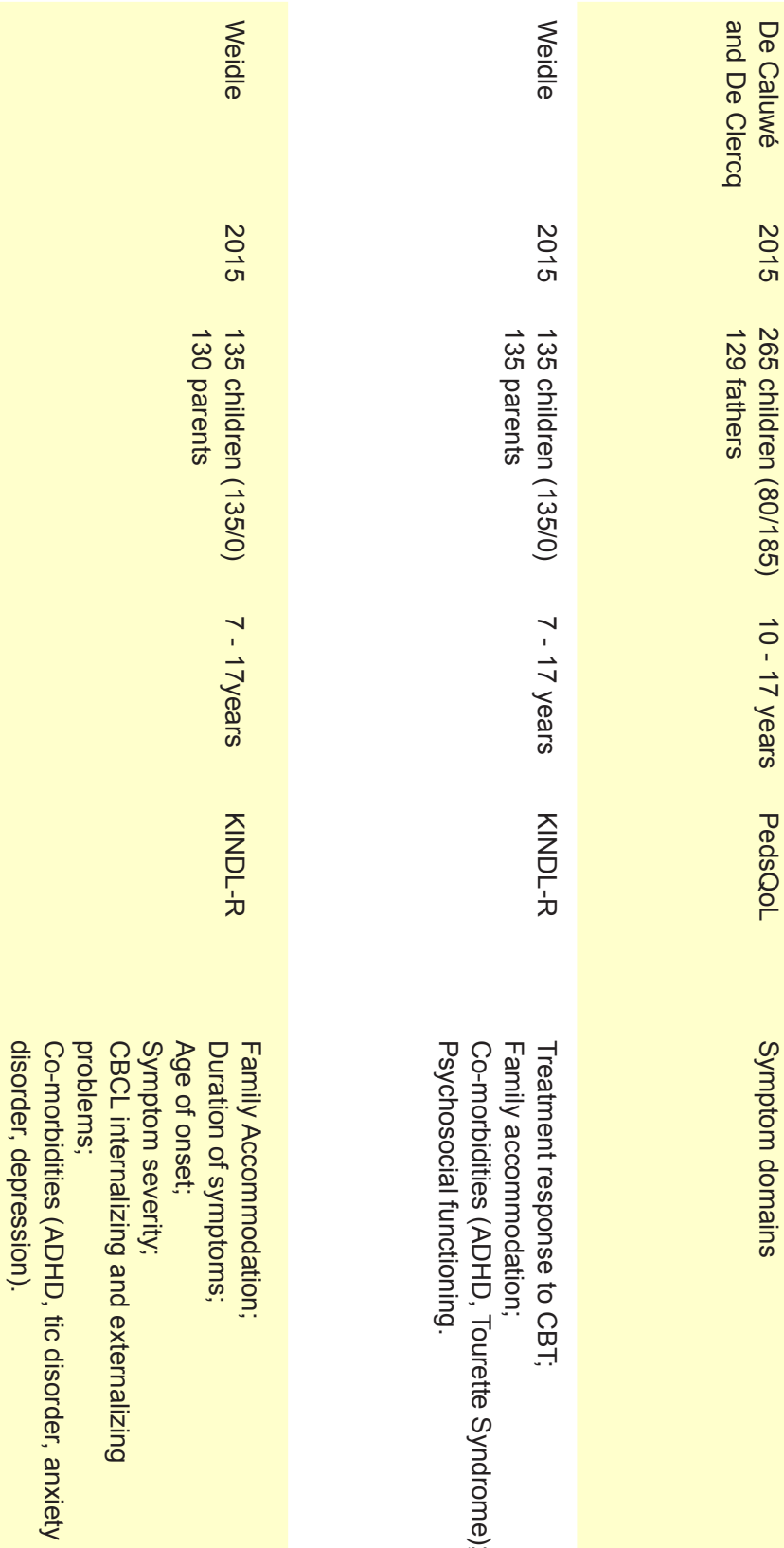

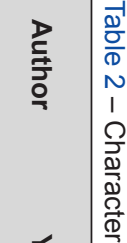

高

$\vec{\omega} \underset{\omega}{\vec{\omega}} \vec{\omega}$

尊 $\frac{?}{\bar{D}}$

急 产

需 $\frac{\overline{2}}{\mathrm{D}}$

耑

$\stackrel{\circ}{\circ}$

照

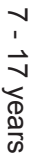

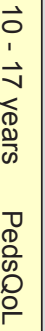

항

$\underset{\substack{\bar{z} \\ \frac{1}{d}}}{\frac{\pi}{d}}$

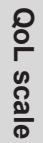

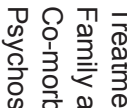

양흐. 융

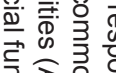

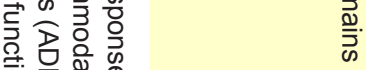

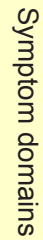

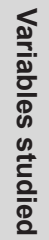

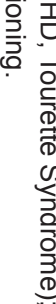

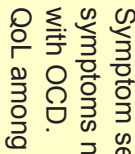

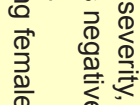

它

○े

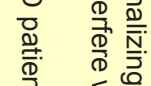

帝 站产

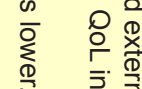

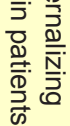
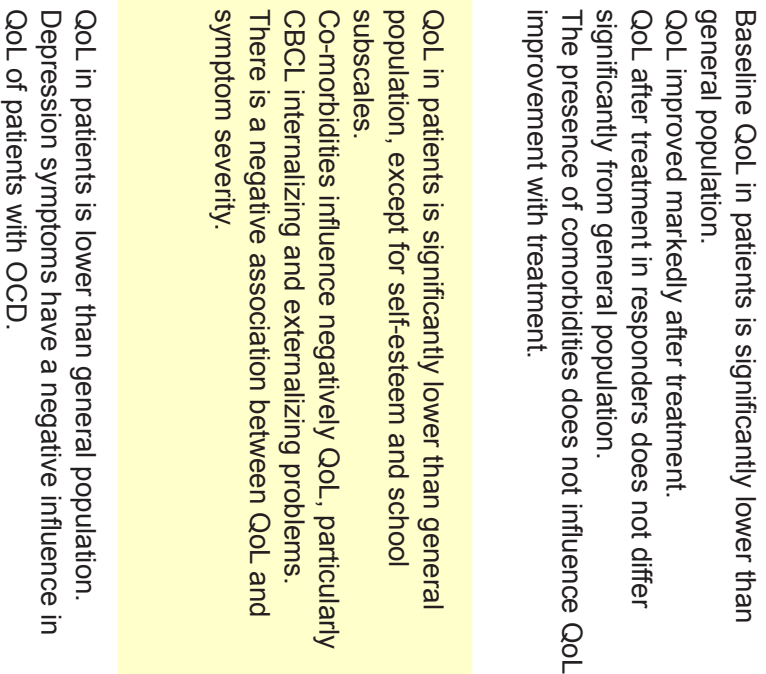

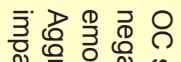

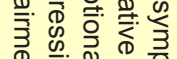

응 응 항

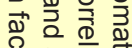

응

के ‥ ㅇ. 웡

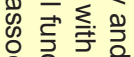

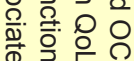

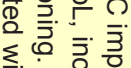

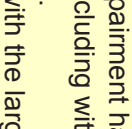

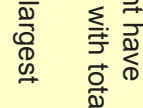

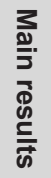

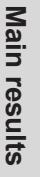


with QoL, mainly with emotional and social subcategories. In this same study published in 2015, they also assessed OCD impairment and their results pointed to a very strong and positive relationship between patients QoL and OCD impairment. OCD impairment is also in turn related with OCD symptom dimension: obsessive symptom domain is again the most influent, being followed by compulsive symptom domain and finally by order/clean/perfect. ${ }^{15}$

\section{Family accommodation and quality of life}

Weidle studied in 2014 the influence of family accommodation (FA) in predicting QoL in children with OCD and he found some different results when analyzing parents and self-reports. Regarding self-report, FA levels was not associated with QoL. However, considering parent proxy reports, a negative correlation was found between FA and all QoL subscales and total score. ${ }^{14}$

\section{Symptoms severity and quality of life}

In order to determine the severity of OCD symptoms, some authors of the articles found, applied the Children's Yale-Brown Obsessive Compulsive Scale (CY-BOCS). ${ }^{16,17}$ De Caluwé and De Clercq assessed this parameter using the Youth Obsessive-Compulsive Symptoms Scale (YOCSS) that evaluates OCD symptomatology and OCD impairment, attending concrete aspects as time occupied/ frequency, interference in functioning, associated distress, disregarding obsessions or refraining from compulsion, and avoidance. $^{15}$

Lack found results highlighting that symptoms severity and QoL have a mild to moderate correlation that reaches significance in all the categories (social, school and emotional) except physical functioning. ${ }^{16}$ Also Weidle had similar results with symptom severity significantly decreasing QoL total score and the subscales emotional well-being, friends, school, and disorder. ${ }^{14}$ On the other hand, Vivian found some different results: symptom severity tends to lower QoL but with no statistical significance. Besides that, some participants in the study showed a significant reduction in the CY-BOCS score after treatment without concomitant improvement in QoL. ${ }^{12}$

\section{How parents see their children's quality of life}

Not all studies assessed QoL in the same way. De Caluwé and De Clerq applied their questionnaire to children and their fathers. ${ }^{15}$ Weidle used the self-report questionnaire and a proxy version for one of the parents in both trials. ${ }^{13,14}$ The same procedure was used by Lack. ${ }^{16}$ Vivian only assessed adolescents' reports. ${ }^{12}$

Only some of the studies stated the agreement between self and parent-report. The ones that $\operatorname{did}^{13,14,16}$ concluded that parents tend to rate their children's QoL at lower levels than the youth. However this difference does not reach statistical significance and there is an overall agreement between children's and parents report. Lack found that the differences between the two assessments are due to the influence of internalizing symptoms. ${ }^{16}$ Weidle also noticed that children reported their quality of life as better than their caregivers. ${ }^{13,14}$

\section{Quality of Life after treatment}

Weidle studied QoL in children with OCD before and after a 14 session's treatment that consisted of weekly individual cognitive behavioral therapy (CBT) with exposure and response prevention (E/RP) that also included parents. Children and their caregivers reported a significant improvement after treatment in responders that reached the same quality of life levels as the general population. ${ }^{13}$

\section{DISCUSSION}

Although there are many articles describing QoL in adults with OCD, very little research considered children with this pathology.

The studies seem to be concordant stating that QoL is globally reduced in pediatric patients with OCD but they are not concordant regarding the subdomains that are most affected. Besides that, only one study related OCD symptoms dimension with QoL. This study concluded that obsessions with aggression/harm are the most involved in decreasing QoL. It would be profitable to match both variables and develop studies analyzing the affection of each subdomain of QoL in each symptom category of OCD so that the treatment may be directed to improve the domain that is most impaired for a certain kind of patient. For instance, a symptom may lead to a severe impairment in the social field and another different symptom may in turn interfere seriously with school performance. Moreover, a deeper knowledge about this correlation would allow the establishment of realistic goals with the patient.

Regarding the severity of symptoms, there is no solid evidence pointing that this variable has a significant relation with QoL. However, there is a tendency to have a decreased QoL (mainly social and emotional) with more severe symptoms. This is congruent with studies made in adults which results demonstrated that symptoms severity negatively interfere with all QoL aspects. ${ }^{18}$

Two studies also concluded that functional impairment is also very significant and therefore this parameter should be measured independently from QoL in patient's assessment since it is related with QoL but they are not the same thing.

One study found that QoL after treatment in responders becomes almost the same as general population. This finding is congruent with other studies that stated that the remitters of the disease in childhood don't have impairment of their QoL in adulthood and that even non-remitters have their QoL only mild to moderate affected in the future. ${ }^{17}$ However contradictory information is described in articles regarding adults. In this population there is no QoL improvement after treatment. ${ }^{19}$ The fact that children have a shorter duration of the disease and therefore respond better to treatment ${ }^{20}$ may be an explanation. This information may be relevant for the clinicians to explain to patients and their families in order to reach higher levels of treatment compliance and clarify the parents in their concerns about how the disease 
may affect the future of their children's well-being. However, further studies with the aim of evaluating if this improvement happens in all OCD symptoms dimensions should be done.

The results regarding the relation between $\mathrm{QoL}$ and gender or sex are not conclusive but apparently there is a tendency reported by one study for girls to have a lower QoL. This may be related with the fact that women present more internalizing symptoms, ${ }^{21}$ a condition that in this review is concluded to be related with lower QoL.

The finding that only $8 \%$ of the reduction in QoL in pediatric OCD is attributable to the pathology may apparently contradict the empirical knowledge but indeed it is congruent with the fact that QoL in children is influenced by a wide range of factors as the familiar surroundings and education. ${ }^{22}$

The majority of the studies are concordant in stating that the presence of co-morbidities decreases QoL in children with OCD but the co-morbidities analyzed in the papers retrieved were not always the same. Depression, ADHD and tic disorder proved to have a negative influence in QoL. Other studies had already described a decrease in QoL in adults with OCD with an associated Depression. ${ }^{23}$ Another study developed in children with Tourette syndrome analyzed the influence of ADHD and OCD as co-morbidities in QoL and also found that it was more impaired comparing with 'pure' disease. ${ }^{24}$ These findings highlight the relevance of applying a treatment directed not only for the main diagnostic but also for the comorbidities and of assessing their influence in patients' QoL.

Two studies ${ }^{14,16}$ showed that internalizing behavior problems are responsible for a significant impairment in QoL in children with OCD. In this sense, therapeutic strategies must be applied in order to minimize the influence of these symptoms and improve QoL in patients that present this kind of behaviors.

The analysis of some studies show us that parents tend to rate their children's QoL lower than themselves. ${ }^{13,14,16}$ This may be explained by the fact that children do not have a total insight about their condition and capacity of perceiving the difficulties, so they may minimize the impact of the disease in their lives. This highlights the necessity of always assessing the children and their parents' point of view and perception, not only in future research but also in clinical practice.

Several limitations should be noted in this article. The number of articles included is far from optimal. In fact, the selection process was very restricted in function of the few number of articles published regarding this subject. This may make it very difficult to take any kind of conclusions and impairs the validity of them. Besides that, is not possible to construct a meta-analysis about this theme.

Is also important to note how heterogeneous the methodology applied by the different authors is. The first point of discrepancy is that the studies use different instruments to access quality of life. These different tools also have different subscales. Therefore, it is not possible to compare directly the results between studies since the dimensions evaluated are different. The second point falls in the methodology used since some articles applied the questionnaire indifferently to mothers or fathers, one article only to fathers and another did not assess the caregiver's notion. This may lead to alteration of the results and, once again, does not allow for reliable comparisons. The third point is that this review includes studies conducted before the reformulation of the diagnostic criteria for OCD. Therefore here may be included conclusions about people who no longer belong to this category of mental illnesses.

We couldn't find any other review about our subject and is important to note that this paper made a very large overview about the variables related with quality of life in children with OCD based on a deep research for papers in different databases for this subject. Therefore, a very considerable amount of the currently existing literature is here explored and correlated.

All the findings in this review highlight the importance of analyzing QoL in the assessment of children with OCD since it is impaired may have many implications in the treatment approach. Besides that, many other conditions as the presence of comorbidities must be explored and its influence in children's QoL in order to improve it.

\section{CONCLUSION}

With this analysis we can conclude that QoL in children with OCD has decreased and that some clinical variables are related with this impairment but the number of studies analyzing and supporting this information is very low. We can't extrapolate the results and conclusions made for OCD in adulthood to childhood and more efforts must be done in order to develop researches to explore this pediatric area. It's necessary to have standardized and uniform methodologies and instruments so that conclusions about this subject can be taken

This review also highlights the importance of making individual and achievable targets for each patient depending on the symptoms and other clinical variables. Most of all, turning QoL into a separated treatment outcome would allow clinicians to make a more complete and reliable assessment. In this sense, the construction of a specific scale of Quality of Life for OCD population could be very helpful.

\section{CONFLICT OF INTERESTS}

The authors declare that there are no conflicts of interest in this work.

\section{FUNDING SOURCES}

No subsidies or grants contributed to this work. 


\section{REFERENCES}

1. Krebs G, Heyman I. Obsessive-compulsive disorder in children and adolescents. Arch Dis Child. 2015;100:495-9.

2. Boileau B. A review of obsessive-compulsive disorder in children and adolescents. Dialogues Clin Neurosci. 2011;13:401-11.

3. Walitza S, Melfsen S, Jans T, Zellmann H, Wewetzer C, Warnke A. Obsessive-compulsive disorder in children and adolescents. Dtsch Arztebl Int. 2011;108:173-9.

4. Morgado P, Freitas D, Bessa JM, Sousa N, Cerqueira JJ. Perceived stress in obsessive-compulsive disorder is related with obsessive but not compulsive symptoms. Front Psychiatry. 2013;4:21.

5. Diagnostic and Statistical Manual of Mental Disorders. $5^{\text {th }}$ edition. Arlington: American Psychiatric Association; 2013.

6. World Health Organization. The ICD-10 Classification of Mental and Behavioural Disorders: Clinical Descriptions and Diagnostic Guidelines. $10^{\text {th }}$ ed. Geneva. WHO; 1993.

7. Flament MF, Whitaker A, Rapoport JL, Davies M, Berg CZ, Kalikow K, et al. Obsessive compulsive disorder in adolescence: an epidemiological study. J Am Acad Child Adolesc Psychiatry. 1988;27:764-71.

8. Geller DA. Obsessive-compulsive and spectrum disorders in children and adolescents. Psychiatr Clin North Am. 2006;29:353-70.

9. Murray CL. The global burden of disease: a comprehensive asessment of mortality and disability from diseases, injuries and risk factors in 1990 and projected to 2020. Cambridge: Harvard University Press; 1996.

10. Ravens-Sieberer U, Karow A, Barthel D, Klasen F. How to assess quality of life in child and adolescent psychiatry. Dialogues Clin Neurosci. 2014;16:147-58.

11. Fleck MP. O instrumento de avaliação de qualidade de vida da Organização Mundial da Saúde (WHOQOL-100): características e perspectivas. Ciência Saúde Colet. 2000;5:33-8.

12. Vivan AS, Rodrigues L, Wendt G, Bicca MG, Cordioli AV. Quality of life in adolescents with obsessive-compulsive disorder. Rev Bras Psiquiatr. 2013;35:369-74

13. Weidle B, Ivarsson T, Thomsen PH, Lydersen S, Jozefiak T. Quality of life in children with OCD before and after treatment. Eur Child Adolesc Psychiatry. 2015;24:1061-74.

14. Weidle B, Jozefiak T, Ivarsson T, Thomsen PH. Quality of life in children with OCD with and without comorbidity. Health Qual Life Outcomes. 2014;12:152

15. De Caluwe E, De Clercq B. Obsessive-compulsive symptoms in children and adolescents: symptomatology, impairment and quality of life. BMJ. 2015;24:1389-98.

16. Lack CW, Storch EA, Keeley ML, Geffken GR, Ricketts ED, Murphy TK, et al. Quality of life in children and adolescents with obsessivecompulsive disorder: base rates, parent-child agreement, and clinical correlates. Soc Psychiatry Psychiatr Epidemiol. 2009;44:935-42.

17. Palermo $\mathrm{SD}$, Bloch $\mathrm{MH}$, Craiglow $B$, Landeros-Weisenberger $A$, Dombrowski PA, Panza K, et al. Predictors of early adulthood quality of life in children with obsessive-compulsive disorder. Soc Psychiatry Psychiatr Epidemiol. 2011;46:291-7.

18. Eisen JL, Mancebo MA, Pinto A, Coles ME, Pagano ME, Stout R, et al. Impact of obsessive-compulsive disorder on quality of life. Compr Psychiatry. 2006;47:270-5.

19. Moritz S, Rufer M, Fricke S, Karow A, Morfeld M, Jelinek L, et al. Quality of life in obsessive-compulsive disorder before and after treatment. Compr Psychiatry. 2005;46:453-9.

20. Micali N, Heyman I, Perez M, Hilton K, Nakatani E, Turner C, et al. Long-term outcomes of obsessive-compulsive disorder: follow-up of 142 children and adolescents. Br J Psychiatry. 2010;197:128-34.

21. Kessler RC, McGonagle KA, Swartz M, Blazer DG, Nelson CB. Sex and depression in the National Comorbidity Survey. I: Lifetime prevalence, chronicity and recurrence. J Affect Disord. 1993;29:85-96.

22. Bastiaansen D, Koot HM, Ferdinand RF. Psychopathology in children: Improvement of quality of life without psychiatric symptom reduction? Eur Child Adolesc Psychiatry. 2005;14:364-70.

23. Macy AS, Theo JN, Kaufmann SC, Ghazzaoui RB, Pawlowski PA, Fakhry HI, et al. Quality of life in obsessive compulsive disorder. CNS Spectrums. 2013;18:21-33

24. Eddy CM, Cavanna AE, Gulisano M, Calì P, Robertson MM, Rizzo R. The effects of comorbid obsessive-compulsive disorder and attentiondeficit hyperactivity disorder on quality of life in Tourette syndrome. J Neuropsychiatry Clin Neurosci. 2012;24:458-62. 